\title{
La relación profesor-alumno en la Maestría de Enfermedades Infecciosas y Zoonóticas
}

Lourdes Enríquez de Madrid' Annabelle Ferrera ${ }^{2}$

\section{$\mathrm{PCl}$ ¿Qué orientación académica reciben los alumnos al iniciar la Maestría en Enfermedades Infecciosas y Zoonóticas por parte de los profesores? ¿Existe algún tipo de inducción previa?}

LEM/ La Maestría comienza con la orientación a los postulantes desde que son aspirantes al posgrado. Realizamos el anuncio de que iniciará una nueva promoción y los aspirantes vienen a la oficina y se comunican con los coordinadores, quienes les explican la esencia del posgrado: la disciplina que exige, la característica de ser un posgrado en investigación, las regulaciones y su estructura. Luego, se realiza una entrevista a profundidad con los aspirantes para trabajar con ellos y saber si realmente están interesados en desarrollar este posgrado. Además, contestamos todas las preguntas que los aspirantes hacen para que conozcan el posgrado. Y así se va conduciendo el proceso con todos los aspirantes, hasta que llegamos a la definición de la evaluación por los puntajes para la aceptación. No tenemos un propedéutico propiamente, pero realizamos un proceso de inducción a través de reuniones con los asesores y egresados, presentación de proyectos. Asimismo, realizamos reuniones previas en las cuales les damos a conocer experiencias vividas dentro del posgrado.

AFI El posgrado se rige por sus propios reglamentos y normativas. El proceso comienza con la postulación, seguidamente se llevan a cabo entrevistas individualizadas con los aspirantes en las que se les explica la manera en que

\footnotetext{
${ }^{1}$ Microbióloga hondureña. Licenciada en Microbiología y Química Clínica por la Universidad Nacional Autónoma de Honduras; con estudios de Maestría en Biotecnología por la Universidad Nacional Autónoma de México. También posee un Posgrado en Metodología de la Investigación por el Centro de Estudios Perinatales en Argentina. Tiene investigaciones sobre caracterización de bacterias ácido-lácticas, E. coli y gestión de la investigación. Actualmente se desempeña como directora del Instituto de Investigaciones Microbiológicas y es representante de institutos ante el Consejo General de Investigación.

${ }^{2}$ Bióloga hondureña. Licenciada en Biología por la Universidad Nacional Autónoma de Honduras, con estudios de Maestría en Biología Molecular por la Universidad de Bruselas. Posee un doctorado en Microbiología Molecular por la Universidad de Nijmegen. Es profesora titular IV de la Facultad de Ciencias, en la Escuela de Microbiología e investigadora sobre temas como papiloma virus, rotavirus y enfermedades de transmisión sexual. Recientemente ha sido galardona como premio de investigación de larga trayectoria, UNAH, 2014. Actualmente labora como profesora en la Escuela de Microbiología y en la Maestría de Enfermedades Infecciosas y Zoonóticas.
} 
funciona la maestría en cuanto a programación, módulos a cursar por año, líneas de investigación e investigaciones en curso en las cuales ellos pueden insertarse, el código de ética del posgrado, la bioseguridad en trabajos prácticos, entre otros. Además, se enfatizan los enfoques conceptuales de la disciplina elegida por cada uno de los alumnos; también se enfocan los valores sobre los cuales se construye la vida académica de un posgrado. De igual forma, los estudiantes conocen los programas de las asignaturas y los criterios de evaluación que serán utilizados en cada curso.

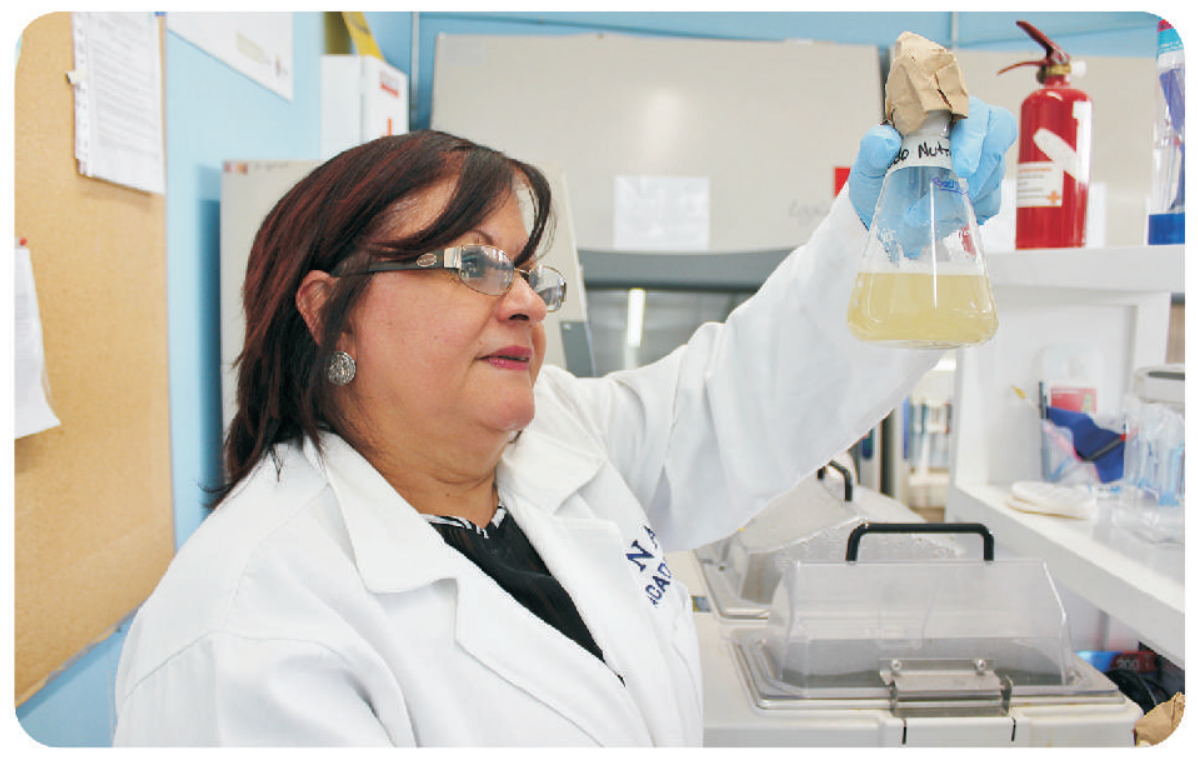

Lourdes Enríquez de Madrid

$\mathrm{PCl}$ ¿Puede describirnos en qué aspectos se fortalece la relación profesoralumno durante a la elaboración de las tesis en la maestría?

LEM/ Este posgrado desarrolla una relación intensa entre profesor y alumno. En primer lugar, porque son pocos los aspirantes que se aceptan. No se puede aceptar un número muy grande de estudiantes porque requerimos de un número adecuado de asesores. La naturaleza del posgrado es de investigación y tenemos el compromiso de que todos nuestros aspirantes aceptados deberán graduarse en el periodo establecido de 2 años, por lo que necesitamos que tengan un seguimiento muy individualizado por parte del asesor. En el proceso de aceptación, lo que hacemos es presentar a los posibles asesores y los proyectos que están en ejecución de manera que los aspirantes conozcan los temas de investigación en los cuáles se podrán 
insertar, las metodologías de trabajo; al alcanzar un consenso se asignan los asesores a los futuros estudiantes de la Maestría. Desde el primer momento existe una vinculación entre el asesor de tesis y el estudiante. En segundo lugar, el plan de estudios contempla el proceso de desarrollo de la tesis, de tal manera que en el primer año los estudiantes desarrollan sus primeros tres capítulos de la tesis y en cada seminario de investigación van presentando sus avances. Así, en el segundo año los estudiantes desarrollan su parte experimental y de análisis de resultados hasta llegar al sexto módulo donde discuten los resultados de su tesis. A lo largo de todo el proceso se requiere una intensa relación con su respectivo asesor, los estudiantes están comunicándose y trabajando con su asesor día a día, para lograr en conjunto la meta propuesta.

AFI En mi caso, hasta el momento he tenido tres alumnos a los cuales he asesorado. Pienso que el asesor se convierte en un soporte y compañía durante todo el periodo de implementación y desarrollo de la tesis. Se establece una especie de sinergia entre las capacidades y fortalezas del asesor, las cuales le brindan al estudiante la posibilidad de obtener una formación más completa de acuerdo al perfil del programa de investigación que está desarrollando. También se les brinda capacidades de innovar, transferir y evaluar los resultados en el contexto de la práctica. A medida que van avanzando adquieren bases sólidas para desarrollar la investigación en el área que ha elegido el estudiante. De igual forma, se llevan a cabo revisiones semanales con ellos, generando un mayor contacto directo. Se discuten avances y los problemas que se han encontrado en el desarrollo de la tesis, tratando de encontrar posibles soluciones. Otro aspecto que desarrollamos es la capacidad para que el estudiante soporte críticas a su trabajo junto con la habilidad de realizar un artículo en el proceso de elaboración de la tesis, ya que también es importante que desarrollen la escritura académica.

\section{$\mathrm{PCl}$ ¿Qué papel tienen los estudiantes en el desarrollo de "papers" académicos dentro de la maestría?}

LEM/ Se promueve fuertemente la escritura y las publicaciones. Ellos van haciendo su revisión de documentos y marco teórico durante el primer año. En ese momento también se les imparte un curso de redacción de publicaciones científicas, presentaciones cortas, diseños de póster. Ellos son el actor fundamental en la escritura de esos documentos. Al final, en el módulo 5, ellos son evaluados por un documento. Algunos de estos artículos los hemos enviado para su publicación, otros han quedado para ser expuestos en póster y otros eventos académicos. 
AFI Como parte de la formación académica existe un módulo de redacción científica en donde se dan las bases de redacción, documentación y búsqueda bibliográfica que preparan al estudiante para la redacción de un artículo científico. También se promueve la participación activa, ya que se les incentiva a que dentro del plazo establecido durante el posgrado se culmine con el envío de un artículo para su publicación. En el posgrado se promueve la participación en eventos académicos y especializados donde se socializan y discuten los resultados de investigaciones. Todos estos ejercicios son importantes en el aprendizaje de los estudiantes.

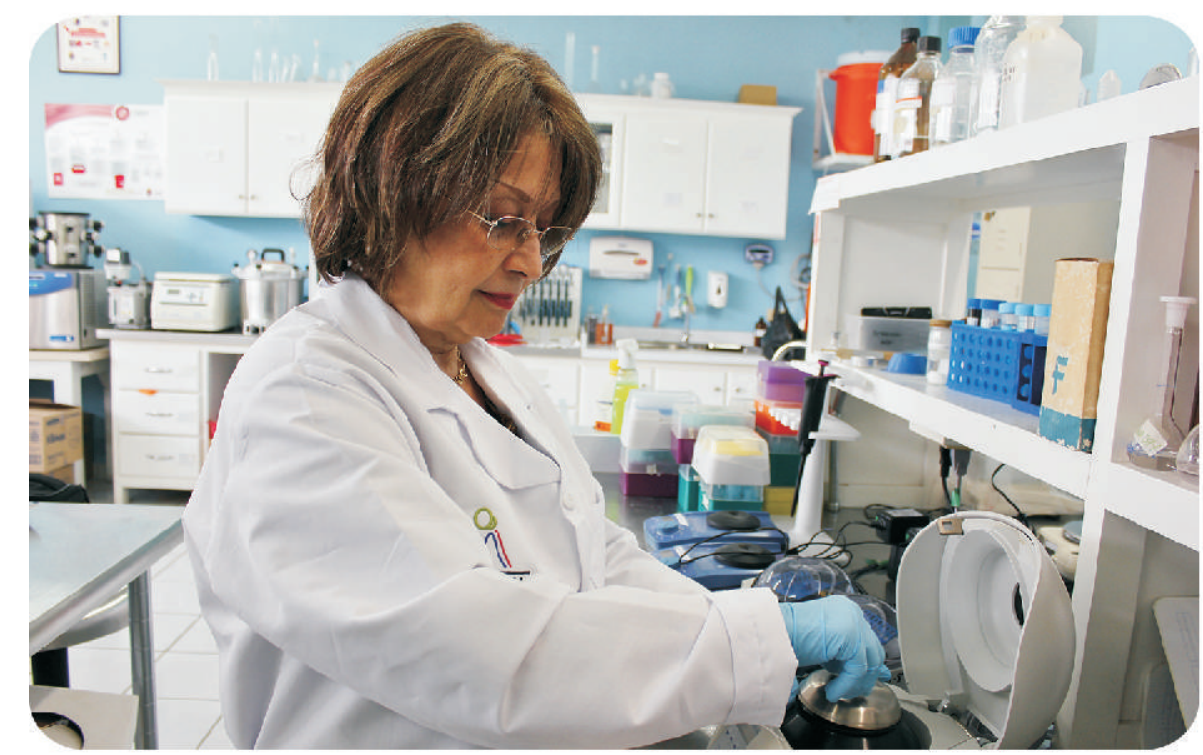

Annabelle Ferrera

$\mathrm{PCl}$ ¿De qué manera los estudiantes colaboran con los profesores en eventos que permiten la internacionalización del posgrado, tales como congresos, conferencias, seminarios y pasantías, entre otras?

LEM/Es importante que los estudiantes participen en todos los eventos que estén a nuestro alcance. Para el caso, en las dos promociones hemos logrado que todos los estudiantes realicen pasantías en el exterior. Gracias a las gestiones de sus asesores, todos han logrado realizar una pasantía, un curso corto o la parte experimental de su tesis en universidades fuera del país. Podemos mencionar Colombia, México, Costa Rica, Nicaragua, Brasil, Canadá y Estados Unidos, logros alcanzados a través de los contactos académicos de los asesores y con diferentes programas de cooperación. 
También los hemos hecho participes de la organización de eventos; por ejemplo, con la primera promoción organizamos un evento internacional en Santa Rosa de Copán y ellos fueron parte de la organización. Con la segunda promoción se organizó un encuentro de posgrados de Microbiología, en la ciudad de León, donde nuestros estudiantes participaron llevando ponencias de sus resultados en investigación. Igualmente, los motivamos a que participen en las jornadas científicas nacionales. Además, el coordinador de investigación y la coordinación académica siempre está enviando información sobre las oportunidades para formación académica en el exterior. Por último, debemos mencionar que dos de nuestros estudiantes ganaron becas para el intercambio de la Red de Macrouniversidades este año.

AFI Como asesor uno debe mantenerse alerta o actualizado sobre las áreas de interés del posgrado, identificando cursos, talleres o estancias de investigación que proporcionen a los estudiantes nuevos conocimientos y herramientas. El papel del asesor es incentivar a que sus alumnos puedan participar en estos eventos. Se promueve su participación en actividades científicas a través de congresos o intercambios internacionales para que difundan sus trabajos por medio de carteles científicos, conferencias, mesas de trabajo o seminarios.

\section{PCl ¿De qué manera los profesores apoyan a los estudiantes de posgrado a continuar con su formación académica y profesional? ¿Siguen existiendo vínculos entre profesores y alumnos?}

LEM/ En algún momento se mantienen los vínculos. Hay quienes han permanecido realizando investigaciones con sus asesores, se han quedado laborando con nosotros. No solamente en la Escuela de Microbiología, sino también en otros departamentos, porque nuestro posgrado es multidisciplinario y algunos de ellos se han incorporado a los grupos de investigación existentes en la Escuela de Microbiología. Los asesores siempre están motivando a los estudiantes; incluso, desde antes que terminen el posgrado ya se van identificando quienes están en condiciones y demuestran interés en desarrollar un doctorado. Se les apoya y colabora en la gestión de oportunidades para el desarrollo de los alumnos.

AFI Con los alumnos que he supervisado los vínculos han sido excelentes. De hecho, uno de ellos está participando activamente en un proyecto de investigación multicéntrico que estamos desarrollando actualmente. Dentro de ese mismo proyecto se le ha enviado a capacitarse en el exterior y también 
se le está instando para que aplique a un curso de epidemiología molecular que tendrá lugar en el extranjero, donde se encuentra la organización que financia esta investigación. Siempre se les está motivando a que prosigan su formación con un doctorado, alertándoles cuando existen posibles convocatorias. Por tanto, la relación siempre ha sido estrecha entre profesores y alumnos durante todo el posgrado y cuando egresan del mismo.

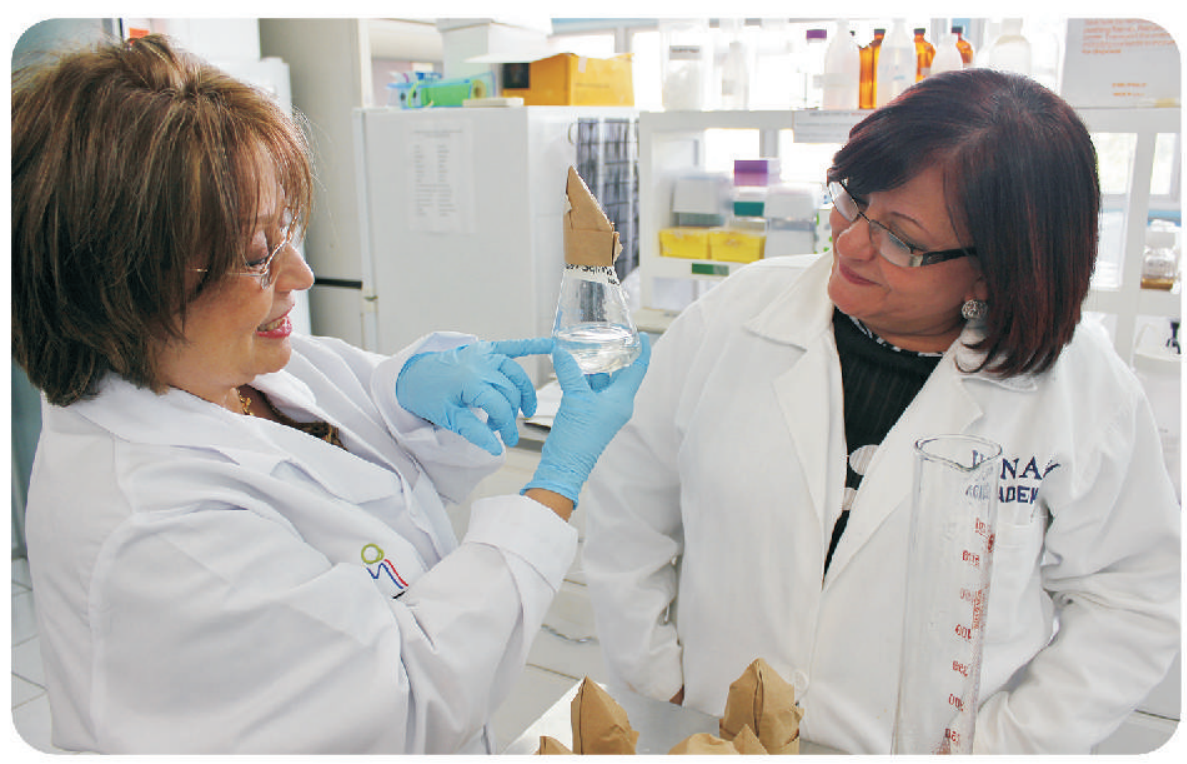

Lourdes Enríquez de Madrid y Annabelle Ferrera 